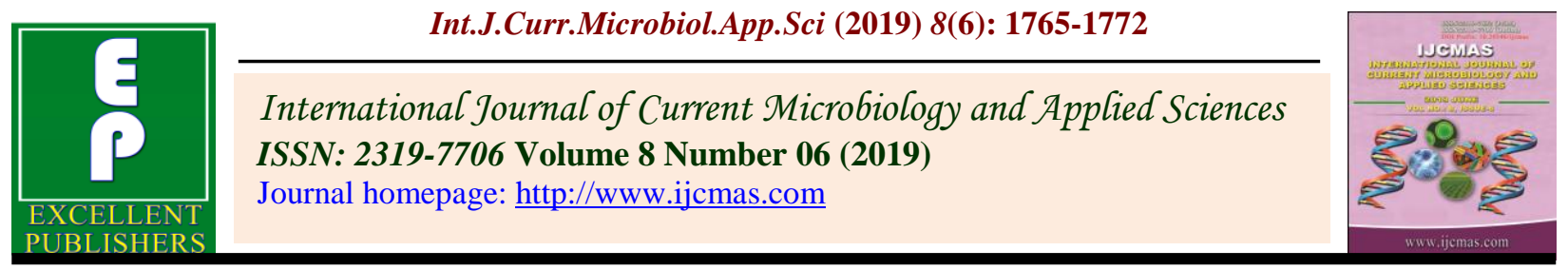

Original Research Article

https://doi.org/10.20546/ijcmas.2019.806.211

\title{
Identification of Trichoderma Isolates from Tobacco Growing Regions of West Godavari District, Based on Sequence Analysis of ITS Region of rDNA and Morphological Variations in the Strains
}

\author{
Santosh Swamy ${ }^{1,3}$, U. Sreedhar ${ }^{2,3}$, R.D. Prasad ${ }^{4}$, B.S.R. Reddy ${ }^{1}$ and P. Sudhakar ${ }^{3}$ \\ ${ }^{1}$ Research Department, Agri Business Division, ITC Limited, \\ Rajahmundry 533 103, A.P, India \\ ${ }^{2}$ Central Tobacco Research Institute, Rajahmundry, A.P, India \\ ${ }^{3}$ Department of Biotechnology, Acharya Nagarjuna University, \\ Nagarjuna Nagar, Guntur, A.P., India \\ ${ }^{4}$ Indian Institute of Oilseeds Research, Rajendranagar, Hyderabad, Telangana, India
}

*Corresponding author

A B S T R A C T

\begin{tabular}{|l|}
\hline Ke y w or d s \\
Trichoderma, \\
Amplification, \\
Distribution
\end{tabular}

The aim of this study was to determine the phylogenetic relationships of Trichoderma isolates obtained from NLS Tobacco region. Utilizing the sequence analysis of internal transcribed spacer-1 (ITS-1) region of the ribosomal DNA the rDNA of Five Trichoderma isolates was amplified by polymerase chain reaction (PCR) using universal primers (ITS-1 and ITS-4). PCR products were purified and these purified products were used to amplify the ITS-4 region of the five Trichoderma isolates. The amplified DNA was sequenced and aligned against ex-type strain sequences from TrichoBLAST and established Trichoderma taxonomy. Two isolates were positively identified as Trichoderma harzianum and three isolates were identified as Trichoderma aesperulum which were used as an outgroup in these analyses. The ITS-1 region sequences have been used as the reference's sequence and this could be further used for future study involving the identification and taxonomy of Trichoderma Amplification of ITS-1 region of the rDNA. This method proved as a rapid and reliable technique for identifying Trichoderma strains successfully.

\section{Introduction}

The genus Trichoderma contains species that are of great economic importance due to their ability to act as biological control agents against a large variety of fungal plant pathogens (Sharma and Singh 2014). The largest distribution of Trichoderma bioproducts is found in Asia, succeeded by Europe, South-Central America and North
America (Sheridan et al., 2014). Biological control using microbial antagonists is considered as a good alternative of management of root diseases in many crops (Dileep et al., 1999; Mukhopadhyay et al., 1992; Sheela et al., 1998; Khot et al., 1996; Gholve and Kurundkar 2002). Trichoderma, commonly available in soil and root ecosystem, has gained immense importance since last few decades due to its biological 
control ability against several plant pathogens (Shahid et al., 2014). Accurate and definitive fungal identification is essential for correct disease diagnosis and treatment of associated fungal infections. Characterization of fungal species using classical methods is not as specific as the genotyping methods. Genotypic techniques involve the amplification of a phylogenetically informative target, such as the small-subunit (18S) rRNA gene (Woese et al., 1977). The Internal Transcribed Spacer (ITS) regions of the rDNA are perhaps the most widely sequenced DNA regions in fungi. It has typically been most useful for molecular systematic study at the species level, and even within species (Ospina-Giraldo et al., 1998; Kubicek et al., 2000; Kulling et al., 2002; Lee and Hseu, 2002). Kindermann et al., (1998) attempted a first phylogenetic analysis of the whole genus of Trichoderma using sequence analysis of the ITS-1 region of rDNA. The sequences of rRNA and proteins comprising the ribosome are highly conserved throughout evolution because they require complex interand intra-molecular interactions to maintain the protein-synthesizing machinery (Sacchi et al., 2002; Hillis et al., 1991; Woese, 1987).

\section{Materials and Methods}

\section{Isolation of Trichoderma from soil sample}

The rhizosphere soil sample was collected from various Tobacco growing fields of West Godavari District of Andhra Pradesh, India. The strains were isolated and identified in Potato Dextrose Agar (PDA) with low sugar medium by serial dilution method (Johnson and Crul, 1972; Nirenberg, 1976).

\section{Conidial morphology- spore size}

The variation in spore sizes of the five isolates of Trichoderma were identified through Phase contrast microscopy. Carl
Ziess, Axioskop 2 Plus, microscope was used and the spore shape was determined using Axioscope 4.0 software.

\section{Genomic DNA extraction from isolates of Trichoderma}

Isolation of fungal genomic DNA was done following standard technique (Raeder, 1985). Fungal mycelia from 3-4 days old culture was crushed with liquid nitrogen and incubated with lysis buffer containing $250 \mathrm{~m}$ MTris- $\mathrm{HCl}$ (pH 8.0), $50 \mathrm{mM}$ EDTA (pH8.0), $100 \mathrm{mM}$ $\mathrm{NaCl}$ and 2\% SDS, for $1 \mathrm{hr}$ at 650C followed by centrifugation at $12,000 \mathrm{rpm}$ for $15 \mathrm{~min}$. The supernatant was extracted with equal volume of water saturated phenol, centrifuged at $12,000 \mathrm{rpm}$ for $15 \mathrm{~min}$, and further extracted with equal volume of phenol: chloroform: isoamyl alcohol $(25: 24: 1)$ by centrifugation at $12000 \mathrm{rpm}$ for $15 \mathrm{~min}$; the aqueous phase was transferred in a fresh tube and chloroform (in the ratioof 1:4 v/v) was added followed by $0.5 \mathrm{M}$ Na-acetate (inthe ratio of 1:10 v/v). Next Isopropanol was added to the above mixture ( 0.7 times the final volume) and centrifuged. DNA was precipitated from the aqueous phase with chilled ethanol (100\%) and pelleted by centrifuging at $12000 \mathrm{rpm}$ for $15 \mathrm{~min}$ followed by washing in $70 \%$ ethanol and centrifugation. The pellets were air dried and suspended in TE buffer $\mathrm{pH} 8$.

\section{Molecular characterization}

The strains were then identified at the molecular level using PCR amplification of the specific gene sequence with universal primer set ITS-1 (forward) and ITS-4 (reverse) sequenced and identified using NCBI BLAST. Ten microlitres of the reaction mixture was then analyzed by submarine gel electrophoresis using $1.0 \%$ agarose with Ethidium Bromide (EtBr) at $8 \mathrm{~V} / \mathrm{cm}$ and the reaction product was visualized under a UV 
transilluminator. The internal transcribed spacer (ITS) regions of the rDNA repeat from the $3^{\prime}$ end of the $28 \mathrm{~S}$ and the $5^{\prime}$ end of the $28 \mathrm{~S}$ gene were amplified using the two primers, ITS-1 and ITS-4 which were synthesized on the basis of conserved regions of the eukaryotic rRNA gene (White et al., 1990). The PCR-amplification reactions were performed in a $50 \mu \mathrm{l}$ mixture containing 50 $\mathrm{mMKCl}, 20 \mathrm{mM}$, TrisHCl (pH 8.4), $2.0 \mathrm{mM}$ $\mathrm{MgCl} 2, \quad 200 \mu \mathrm{M}$ of each of the four deoxynucleotide triphosphates (dNTPs), 0.2 $\mu \mathrm{mM}$ of each primer, $40 \mathrm{ng} / \mu \mathrm{l}$ of template and $2.5 \mathrm{U}$ of Taq polymerase (Fermentas). The cycle parameters included an initial denaturation for $5 \mathrm{~min}$ at $94^{\circ} \mathrm{C}$, followed by 40 cycles of denaturation for $1 \mathrm{~min}$ at $94^{\circ} \mathrm{C}$, primer annealing for $2 \mathrm{~min}$ at $55^{\circ} \mathrm{C}$, primer extension for $3 \mathrm{~min}$ at $72^{\circ} \mathrm{C}$, and a final extension for $10 \mathrm{~min}$ at $72^{\circ} \mathrm{C}$. Amplified products were separated on $1.2 \%$ agarose gel in TAE buffer, pre-stained with ethidium bromide $(1 \mu \mathrm{g} / \mathrm{ml})$ and electrophoresis was carried out at $60 \mathrm{~V}$ for $3 \mathrm{~h}$ in TAE buffer. One $\mathrm{Kb}$ ladder (MBI, Fementas) was used as a marker. The gel was observed in a transilluminator over ultraviolet light. The desired bands were cut from the gel with a minimum quantity of gel portion using the QIAGEN gel extraction kit. The PCR product was purified by QIAGEN gel extraction kit using the protocol described in the manufacturer's manual. A pair of universal ITS primers ITS-1 (forward) and ITS-4 (reverse) were used for sequencing of the amplified product and this step was carried out at the Merck Laboratory (Bangalore, India). The details of the primers are mentioned in Table 1.

\section{Sequence analysis and phylogeny}

A comparison of the $28 \mathrm{~S}$ rRNA gene sequence of the test strain against nucleotide collection (nr/nt) database was done using BLAST program (Zhang et al., 2000).
Sequences that shared about $90 \%$ similarity with the test sequence were selected for a multiple sequence alignment that was carried out using ClustalW (Thompson et al., 1994). Subsequently, an evolutionary distance matrix was generated from these nucleotide sequences in the dataset. A phylogenetic tree was then constructed using the Neighbourjoining method (Saitou and Nei, 1987). Phylogenetic and molecular evolutionary analyses were conducted using MEGA (Molecular Evolutionary Genetics Analysis) version 4.0 (Tamura et al., 2007).

The 16S rRNA gene sequence of test strain was compared with a different set of sequence databases such as small subunit ribosomal RNA (SSU rRNA) and large subunit ribosomal RNA (LSU rRNA)using Ribosomal RNA BLAST (Altschul et al., 1997). 28S rRNA gene sequence of the test strain was also compared against those sequences, in Ribosomal Database Project (Cole et al., 2009) by using the RDP Classifier check program (Wang et al., 2007). The annotated information for the sequence in the database to which $28 \mathrm{~S}$ rRNA aligns is used for fungal identification. (Soumya $\mathrm{P}$ et al., 2016)

\section{Results and Discussions}

The 5 isolates of Trichoderma were isolated from the rhizosphere of tobacco growing soils of West Godavari District of Andhra Pradesh, India. The strains were isolated and identified in Potato Dextrose Agar (PDA) with low sugar medium by serial dilution method. The morphological differences of the Trichoderma isolates were observed and are tabulated in Table 2. Among the strains strain ITC-04 was distinct from the other four and produced flourocent yellowish green pigmentation, remaining other four strains were found to be green to greenish yellow in colour (Figure 2). Strain ITC-01, ITC-02 and ITC-05 were very 
fast growers and produced luxuriant mycelia, compared to ITC-03 and ITC-04 were slow growers. When spore shape was compared among the strains, ITC-01 and ITC-02 produced round spores while the ITC-03 and ITC-04 produced Oblong spores while the spores of ITC-05 were round to oblong (Figure 3).

Fig.1 Phylogenetic tree of the Trichoderma strains

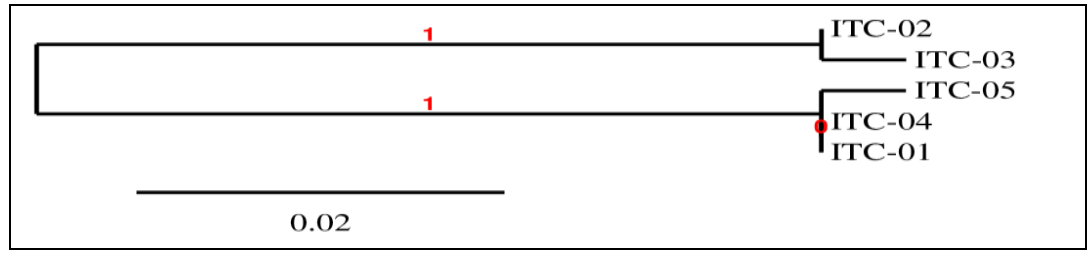

Fig.2 Trichoderma strains on PDA plates

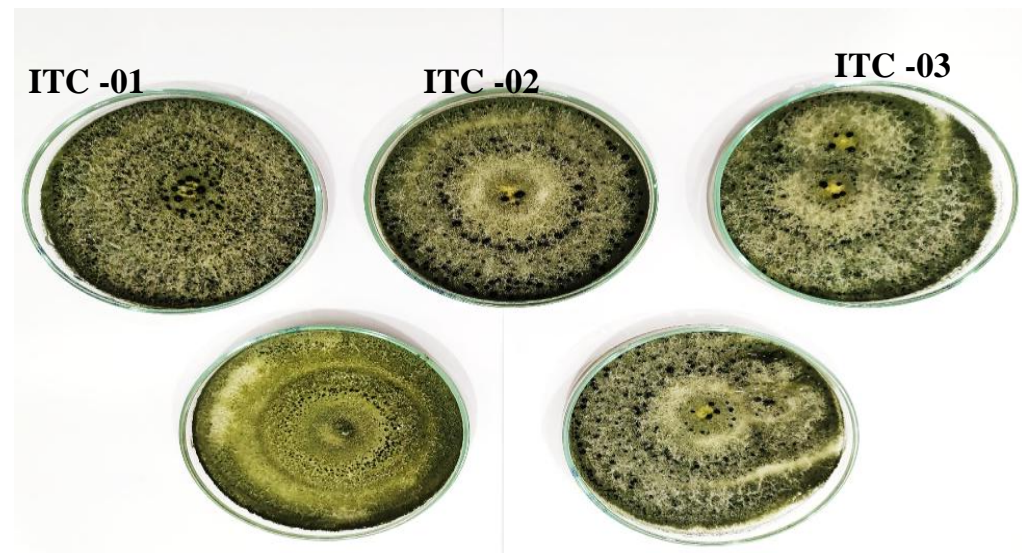

Fig.3 Trichoderma mycelia and spores under microscope

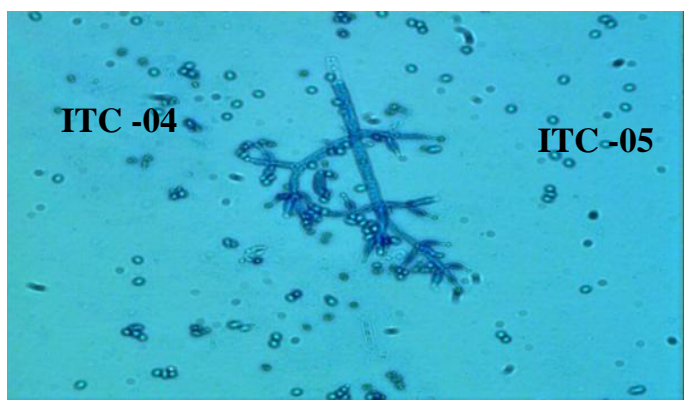

Table.1 Gene sequence with universal primers

\begin{tabular}{|c|c|c|c|c|}
\hline Primer Name & Sequence $\left(\mathbf{5}^{\prime} \mathbf{- 3}\right)$ & Length & Tm $\left({ }^{\circ} \mathbf{C}\right)$ & $\begin{array}{c}\text { GC content } \\
(\mathbf{\%})\end{array}$ \\
\hline ITS-1 & TCTGTAGGTGAACCTGCGG & 19 & 53 & 58 \\
\hline ITS-4 & TCCTCCGCTTATTGATATGC & 20 & 50 & 45 \\
\hline
\end{tabular}


Table.2 Morphological characters of Trichoderma strains

\begin{tabular}{|c|c|c|c|}
\hline \multicolumn{4}{|c|}{ Morphological characters } \\
\hline \multirow[t]{2}{*}{ Isolate } & \multicolumn{3}{|c|}{ Colony characteristics } \\
\hline & Colour & Mycelial growth & Spore shape \\
\hline Trichoderma asperellum (ITC-1) & Green & +++ & Round \\
\hline Trichoderma harzianum (ITC-2) & Green & +++ & Round \\
\hline Trichoderma harzianum (ITC-3) & Greenish Yellow pigmented & ++ & Oblong \\
\hline Trichoderma asperellum (ITC-4) & Florescent Green pigmented & ++ & Oblong \\
\hline Trichoderma asperellum (ITC-5) & Green & +++ & Oblong to Round \\
\hline
\end{tabular}

Table.3 Gene Sequence of the Trichoderma strains

\begin{tabular}{|c|c|}
\hline Isolate & Gene Sequence \\
\hline Trichoderma asperellum(ITC-1) & $\begin{array}{l}\text { AAGTAAAAGTCGTAACAAGGTCTCCGTTGGTGAACCAGCGGAGGGATCATTACCGAG } \\
\text { TTTACAACTCCCAAACCCAATGTGAACGTTACCAAACTGTTGCCTCGGCGGGGTCACG } \\
\text { CCCCGGGTGCGTCGCAGCCCCGGAACCAGGCGCCCGCCGGAGGAACCAACCAAACTC } \\
\text { TTTCTGTAGTCCCCTCGCGGACGTATTTCTTACAGCTCTGAGCAAAAATTCAAAATGA } \\
\text { ATCAAAACTTTCAACAACGGATCTCTTGGTTCTGGCATCGATGAAGAACGCAGCGAA } \\
\text { ATGCGATAAGTAATGTGAATTGCAGAATTCAGTGAATCATCGAATCTTTGAACGCACA } \\
\text { TTGCGCCCGCCAGTATTCTGGCGGGCATGCCTGTCCGAGCGTCATTTCAACCCTCGAA } \\
\text { CCCCTCCGGGGGATCGGCGTTGGGGATCGGGACCCTCACACGGGTGCCGGCCCCGA } \\
\text { AATACAGTGGCGGTCTCGCCGCAGCCTCTCCTGCGCAGTAGTTTGCACAACTCGCACC } \\
\text { GGGAGCGCGGCGCGTCCACGTCCGTAAAACACCCAACTTTCTGAAATGTTG }\end{array}$ \\
\hline Trichoderma harzianum(ITC-2) & $\begin{array}{l}\text { TTGCCTCGGCGGGATCTCTGCCCCGGGTGCGTCGCAGCCCCGGACCAAGGCGCCCGCC } \\
\text { GGAGGACCAACCAAAACTCTTATTGTATACCCCCTCGCGGGTTTTTTTATAATCTGAG } \\
\text { CCTTCTCGGCGCCTCTCGTAGGCGTTTCGAAAATGAATCAAAACTTTCAACAACGGAT } \\
\text { CTCTTGGTTCTGGCATCGATGAAGAACGCAGCGAAATGCGATAAGTAATGTGATTG } \\
\text { CAGAATTCAGTGATCATCGAATCTTTGAACGCACATTGCGCCCGCCAGTATTCTGGC } \\
\text { GGGCATGCCTGTCCGAGCGTCATTTCAACCCTCGAACCCCTCCGGGGGGTCGGCGTTG } \\
\text { GGGATCGGCCCTGCCTTGGCGGTGGCCGTCTCCGAAATACAGYGGCGGTCTCGCCGC } \\
\text { AGCCTCTCCTGCGCAGTAGTTTGCACACTCGCATCGGGASCGCGGCGCGTCCACAGCC } \\
\text { GTTAAACACCCMACTTCTG }\end{array}$ \\
\hline Trichodermaharzianum(ITC-3) & $\begin{array}{l}\text { CTGTCGCCTCGGCGGGATCTCTGCCCCGGGTGCGTCGCAGCCCCGGACCAAGGCGCCC } \\
\text { GCCGGAGGACCAACCAAAACTCTTATTGTATACCCCCTCGCGGGTTTTTTTATAATCT } \\
\text { GAGCCTTCTCGGCGCCTCTCGTAGGCGTTTCGATAATGAATCAAAACTTTCAACAACG } \\
\text { GATCTCTTGGTTCTGGCATCGATGAAGAACGCAGCGAAATGCGATAAGAATGTGAA } \\
\text { TTGCAGAATTCAGTGAATCATCGAATCTTTGAACGCACATTGCGCCCGCCAGTATTCT } \\
\text { GGCGGGCATGCCTGTCCGAGCGTCATTTCAACCCTCGAACCCCCCGGGGGGTCGGCG } \\
\text { TTGGGGATCGGCCCTGCCTTGGCGGTGGCCGTCTCCGAAATACAGYGGCGGTCTCGCC } \\
\text { GCAGCCTCTCCTGCGCAGTAGTTTGCACACTCGCATCGGGASCGCGGCGCGTCCACAG } \\
\text { CCGTTAAACACCCMACTC }\end{array}$ \\
\hline Trichoderma asperellum(ITC-4) & 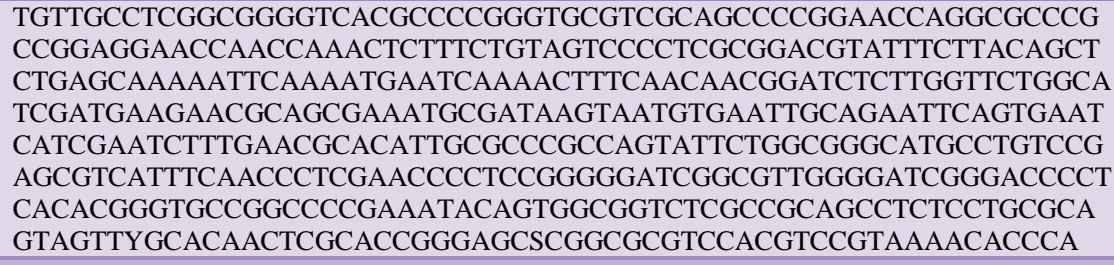 \\
\hline Trichoderma asperellum(ITC-5) & $\begin{array}{l}\text { CGTTACCAAACTGTTGCCTCGGCGGGGTCACGCCCCGGGTGCGTCMAAAGCCCCGGA } \\
\text { ACCAGGCGCCCGCCGGAGGAACCAACCAAACTCTTTCTGTAGTCCCCTCGCGGACGT } \\
\text { ATTTCTTACAGCTCTGAGCAAAAATTCAAAATGAATCAAAACTTTCAACAACGGATCT } \\
\text { CTTGGTTCTGGCATCGATGAAGAACGCAGCGAAATGCGATAAGTAATGGAATGCA } \\
\text { GAATTCAGTGATCATCGAATCTTTGAACGCACATTGCGCCGCCAGTATTCTGGCGG } \\
\text { GCATGCCTGTCCGAGCGTCATTTCAACCCTCGAACCCCTCCGGGGATCGGCGTTGGG } \\
\text { KATCGGGACCCCTCACACGGGTGCCGGCCCCGAAATACAGTGGCGGTCTCGCCGCAG } \\
\text { CCTCTCCTGCGCAGTAGTTTGCACAACTCGCACCGGGAGCGCGGCGCGTCCACGTCCG } \\
\text { TAAAACACCCAACTT }\end{array}$ \\
\hline
\end{tabular}


The ribosomal RNA genes (rDNA) possess characteristics that are suitable for the identification of fungal isolates at the species level. These rDNA are highly stable and exhibit a mosaic of conserved and diverse regions within the genome (Hibbette, 1992). They also occur in multiple copies with up to 200 copies per haploid genome (Bruns et al., 1991; Yao et al., 1992) arranged in tandem repeats with each repeat consisting of the $18 \mathrm{~S}$ small subunit (SSU), the5.8S, and the $28 \mathrm{~S}$ large subunit (LSU) genes. Internal transcribed spacer (ITS) regions have been used successfully to generate specific primers capable of differentiating closely related fungal species [Bryan et al., 1995]. In the broader context, taxon-selective amplification of ITS regions is likely to become a common approach in molecular identification strategies.

In the present study, we focused on the ITS regions of ribosomal genes forthe construction of primers that can be used to identify Trichoderma spp. ITS region of rDNA was amplified using genus-specific ITS-1 and ITS4 primers (Table 3). The Trichoderma isolates were identified based on the amplification of the specific gene sequence with universal primer set ITS-1 (forward) and ITS-4 (reverse) sequenced and identified using NCBI BLAST. As per the BLAST search of the gene sequence given below, the isolates were identified as Trichoderma asperellum (ITC-1), Trichoderma harzianum (ITC-2), Trichoderma harzianum (ITC-3), Trichoderma asperellum (ITC-4) and Trichoderma asperellum (ITC-5). From the phylogenic tree, it was observed that Trichoderma asperellum strains (ITC-1, ITC4 and ITC-5) were clustered together in the same group while Trichoderma harzianum (ITC -2 and ITC-3) were clustered separately in the separate group (Figure 1).

\section{Acknowledgements}

The paper forms a part of the $\mathrm{PhD}$ work at Acharya Nagarjuna University, Guntur, of the first author and the facilities provided by Research Department, Agri Business Division, ITC Limited, Rajahmundry and Indian Institute of Oilseeds Research, Rajendranagar, Hyderabad, for carrying out this research is sincerely acknowledged.

\section{References}

Altschul SF, Madden TL, Schaffer AA, Zhang J, Zhang Z, Miller W, Lipman DJ (1997). Gapped BLAST and PSIBLAST: a new generation of protein database search programs. Nucleic Acids Res. 25(17): 3389-3402.

Bruns, T.D., White T.J., Talyor J.W., 1991. Fungalmolecular systematics. Annu. Rev. Ecol. Sys, 22:525-564.

Bryan, G.T., M.J. Daniels, A.E. Osbourn, 1995.Comparison of fungi within the Gaeumannomyces- Phialophora complex by analysis of ribosomal DNA sequence. Appl. Environ. Microbiol, 61: 681-689.

Cole JR, Wang Q, Cardenas E, Fish J, Chai B, Farris RJ, Kulam-SYED-MOHIDEEN AS, MCGARRELL DM, MARSH T, GARRITY GM, TIEDJE JM (2009). The Ribosomal Database Project: Improved alignments and new tools for rRNA analysis. NucleicAcids Res. 37: D141-D145.

Gelfand DH, Sninsky JJ, White TJ (Eds.), PCR protocols: a guide to methods and applications. Academic Press, Inc., San Diego, Calif. 315-322.

Hibbett, D.S., 1992. Ribosomal RNA and fungal systematics. Trans. Mycol. Soc., 33: 533-556.

Hillis DM, Moritz C, Porter CA, Baker RJ (1991). Evidence for biased gene conversion in concerted evolution of ribosomal DNA. Science 251: 308-310. 
Hiney M, Dawson MT, Heery DM, Smith PR, Gannon F, Powell R (1992). DNA probe for Aeromonas salmonicida. Appl. Environ. Microbiol. 58(3): 10391042.

Johnson LF, Crulea (1972). Methods of research on the ecology of soil-borne pathogens, Minneapolis U.S. Burgess Pub. 247.

Kindermann J, Ayouti YE, Samuels GJ, KUBICEK CP (1998). Phylogeny of the genus Trichoderma based on sequence analysis of the Internal Transcribed Spacer region 1 of the rDNA cluster. Fungal Gen. Biol. 24: 298-309.

Kubicek CP, Mach RL, Peterbauer CK, LORITO M (2000). Trichoderma. From genes to biocontrol. J. Plant Pathol.83: 11-23.

Kulling CM, Szakacs G, Kubicek CP (2002). Phylogeny and evolution of the genus Trichoderma: a multigene approach. Mycol. Res. 106: 757-767.

Lee C, Hseu T (2002). Genetic relatedness of Trichoderma sect. Pachybasium species based on molecular approaches. Can. J. Microb. 48: 831-840.

Nirenberg HI (1976). Studies on the morphological and biological differentiation in Fusarium section Liseola. Mitt BiolBundesanstalt fur Land-Forstw Berlin-Dallem, 169: 1117.

Ospina-Giraldo MD, Royse DJ, Thon MR, Chen X, Romaine CP (1998). Phylogenetic Relationships of Trichodermaharzianum Causing Mushroom Green Mold in Europe and North America to Other Species of Trichoderma from World-Wide Sources. Mycologia 90(1): 76-81.

Raeder, U. and P. Broda, 1985. Rapid preparationof DNA from filamentous fungi. Letters in Applied Microbiology, 1: $17-20$.
Sacchi CT, Whitney AM, Reeves MW, Mayer LW, Popovic T (2002). Sequence Diversity of Neisseria meningitis 16S rRNA Genes and Use of 16S rRNA Gene Sequencing as a Molecular Subtyping Tool. J. Clin. Microbiol. 40(12): 4520-4527.

Saitou N and Nei M (1987). The neighbourjoining method: a new method for reconstructing phylogenetic trees. Mol. Biol. Evol. 4(4): 406-425.

Sowmya P, R D Prasad and Navaneetha T, 2016. "Morphological and biochemical characterization of thermotolerant Trichoderma. Int. Journal of Curr. Res., 8, (09), 38668-38672.

Srivastava S, Singh V, Kumar V, Verma PC, Srivastava R, Basu V, Gupta V, Rawat AK (2008). Identification of regulatory elements in $16 \mathrm{~S}$ rRNA gene of Acinetobacter species isolated from the water sample. Bioinformation 3(4): 173176.

Tamura K, Dudley J, Nei M, Kumar S (2007). MEGA4: Molecular Evolutionary Genetics Analysis (MEGA) software version 4.0. Mol. Biol. Evol. 24(8): 1596-1599.

Thompson JD, Higgins DG, Gibson TJ Clustal W (1994). Improving the sensitivity of progressive multiple sequence alignment through sequence weighting, position-specific gap penalties and weight matrix choice. Nucleic Acids Res. 22(22): 4673-4680.

Wang Q, Garrity GM, Tiedje JM, Cole JR (2007). Naïve Bayesian Classifier for Rapid Assignment of rRNA Sequences into the New Bacterial Taxonomy. Appl. Environ. Microbiol. 73(16): 52615267.

White TJ, Bruns T, Lee S, Taylor J (1990). Amplification and direct sequencing of fungal ribosomal DNA for phylogenetics. In: Innes MA, 
Williams JGK, Kubelik AR, Livak KJ, Rafalski JA, Tingey SV (1990). DNA polymorphisms amplified by arbitrary primers are useful as genetic markers. Nucleic Acid Res.18: 6531-6535.

Woese CR (1987). Bacterial evolution. Microbiol. Rev. 51: 221-271.

Woese CR, Fox GE (1977). Phylogenetic structure of the prokaryotic domain: the primary kingdoms. Proc. Natl. Acad. Sci. USA, 74: 5088-5090.

Yadav V, Prakash S, Srivastava S, Verrna PC, Gupta V, Basu V, Rawat, AK (2009).
Identification of Comamonas species using 16S rRNA gene sequence. Bioinformation 3(9): 381-383.

Yao, C, Frederiksen R.A., Magill C.W., 1992. Length heterogeneity in ITS2 and the methylation status of CCGG and GCGC sites in the rRNAgenes of the genus Peronosclerospora. Curr. Genet.22: 415-420.

Zhang Z, Schwartz S, Wagner L, Miller W (2000). A greedy algorithm for aligning DNA sequences. J. Comput. Biol. 7(12): 203-214.

\section{How to cite this article:}

Santosh Swamy, U. Sreedhar, R.D. Prasad, B.S.R. Reddy and Sudhakar, P. 2019. Identification of Trichoderma Isolates from Tobacco Growing Regions of West Godavari District, Based on Sequence Analysis of ITS Region of rDNA and Morphological Variations in the Strains. Int.J.Curr.Microbiol.App.Sci. 8(06): 1765-1772. doi: https://doi.org/10.20546/ijcmas.2019.806.211 